\title{
Mesenteric ischemia: the importance of differential diagnosis for the surgeon
}

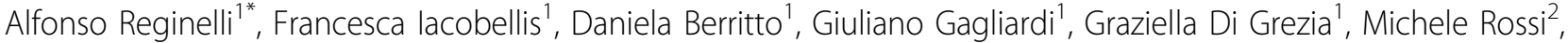 \\ Paolo Fonio ${ }^{3}$, Roberto Grassi ${ }^{1}$
}

From 26th National Congress of the Italian Society of Geriatric Surgery

Naples, Italy. 19-22 June 2013

\begin{abstract}
Background: Intestinal ischemia is an abdominal emergency that accounts for approximately 2\% of gastrointestinal illnesses. It represents a complex of diseases caused by impaired blood perfusion to the small and/ or large bowel including acute arterial mesenteric ischemia (AAMI), acute venous mesenteric ischemia (AVMI), non occlusive mesenteric ischemia (NOMI), ischemia/reperfusion injury (I/R), ischemic colitis (IC). In this study different study methods (US, CT) will be correlated in the detection of mesenteric ischemia imaging findings due to various etiologies.
\end{abstract}

Methods: Basing on our institutions experience, 163 cases of mesenteric ischemia/infarction from various cases, investigated with $\mathrm{CT}$ and undergone surgical treatment were retrospectively evaluated, in particular trought the following findings: presence/absence of arterial/venous obstruction, bowel wall thickness and enhancement, presence/absence of spastic reflex ileus, hypotonic reflex ileus or paralitic ileus, mural and/or portal/mesenteric pneumatosis, abdominal free fluid, parenchymal ischemia/infarction (liver, kidney, spleen).

Results: To make an early diagnosis useful to ensure a correct therapeutic approach, it is very important to differentiate between occlusive (arterial, venous) and non occlusive causes (NOMI). The typical findings of each forms of mesenteric ischemia are explained in the text.

Conclusion: The radiological findings of mesenteric ischemia have different course in case of different etiology. In venous etiology the progression of damage results faster than arterial even if the symptomatology is less acute; bowel wall thickening is an early finding and easy to detect, simplifying the diagnosis. In arterial etiology the damage progression is slower than in venous ischemia, bowel wall thinning is typical but difficult to recognize so diagnosis may be hard. In the NOMI before/without reperfusion the ischemic damage is similar to AAMI with additional involvement of large bowel parenchymatous organs. In reperfusion after NOMI and after AAMI the CT and surgical findings are similar to those of AVMI, and the injured bowel results quite easy to identify. The prompt recognition of each condition is essential to ensure a successful treatment.

\section{Background}

Several pathologies like cancer, diabetes, neurodegenerative and cardiovascular induced by oxidative stress mechanisms occurs frequently in senescence $[1,2]$. Oxidant molecules like NO (Nitric oxide) and ROS (Reactive oxygen species) are overproduced in response to drugs,

\footnotetext{
* Correspondence: reginelli@tin.it

'Department of Internal and Experimental Medicine, Magrassi-Lanzara, Institute of Radiology, Second University of Naples, Naples, Italy Full list of author information is available at the end of the article
}

chemicals, high-caloric diets, exercise and other stress agents [3]. Mesenteric ischemia represents an abdominal emergency accounting for approximately $2 \%$ of gastrointestinal illnesses [4]. Despite recent advances in surgery and intensive therapy its mortality remains very high, ranging between 50-90\% [5]. Patients survival is dependent on prompt recognition and treatment before ischemia progresses to intestinal gangrene [6]. Computed tomography angiography has surpassed angiography as the diagnostic test of choice and represents the gold standard due to its

\section{Biomed Central}

(c) 2013 Reginelli et al; licensee BioMed Central Ltd. This is an open access article distributed under the terms of the Creative Commons Attribution License (http://creativecommons.org/licenses/by/2.0), which permits unrestricted use, distribution, and reproduction in any medium, provided the original work is properly cited. 
ability to define the arterial anatomy and to evaluate secondary signs of mesenteric ischemia, with sensitivity ranging from $82 \%$ to $96 \%$ and specificity of $94 \%$ [7-12]. Unlike chronic mesenteric ischemia, the treatment of acute mesenteric ischemia remains largely surgical. This is due to the emergent need for revascularization combined with an assessment of bowel viability [7]. An alternative approach might consist in injecting the patients with autologous endothelial progenitor cells, to accelerate tissue revascularization and prevent a surgical approach [13-15]. Unfortunately, the therapeutic feasibility of such a strategy would require the elucidation of the biological properties of these rathe promising cells, which is far from being fully achieved [16-20]. Before proceeding with surgical treatment is necessary to establish the correct etiology as mesenteric ischemia represents a complex of diseases including acute arterial mesenteric ischemia (AAMI), acute venous mesenteric ischemia (AVMI), non occlusive mesenteric ischemia (NOMI) and ischemia/reperfusion injury (I/R). Each of these different forms is characterized by a specific clinical and pathologic time course that must be defined and understood to ensure an appropriate treatment and a good outcome[20,21]. So, aim of this work is to analyze the different clinical pictures of acute mesenteric ischemia related to etiology providing the surgeon with a useful discussion of the differences.

\section{Materials and methods}

Basing on our institutions experience, 163 cases of mesenteric ischemia/infarction from various cases, investigated with $\mathrm{CT}$ and undergone surgical treatment were retrospectively evaluated. The following CT findings were considered: patency of the superior mesenteric artery (SMA) or inferior mesenteric artery (IMA), bowel wall thickness (more or less than $3 \mathrm{~mm}$ ) and enhancement, presence/ absence of spastic reflex ileus, hypotonic reflex ileus or paralitic ileus, mural and/or portal/mesenteric pneumatosis, abdominal free fluid, parenchymal ischemia/infarction (liver, kidney, spleen); and the following intraoperative findings: presence of pale/congested mesentery, color of the bowel wall, presence/absence of bowel spasm or dilation, presence/absence of abdominal free fluid, kind of fluid in peritoneal cavity (hemorragic or serous), signs of parenchymal ischemia/infarction (liver, kidney, spleen), extension of the bowel damage. Enhanced CT was performed with 64-detector row configuration (VCT, General Electric Healthcare, Milwaukee, Wis, USA). The following technical parameters were used: in 64-rows CT, effective slice thickness of $3.75 \mathrm{~mm}$ for plain acquisition, $1.25 \mathrm{~mm}$ in the late arterial phase and $2.5 \mathrm{~mm}$ in the portal venous phase; beam pitch of 0.938 , reconstruction interval of 0.8 $\mathrm{mm}$, tube voltage of $120-140 \mathrm{KVp}$ and reference mAs of $250 / 700 \mathrm{~mA}$. Automatic tube current modulation was used to minimize the radiation exposure. A standard reconstruction algorithm was used. Patients were instructed not to breath during helical imaging to avoid motion artefacts. All patients received iodinated nonionic contrast material (iopromide, Ultravist 300, Schering, Berlin, Germany) intravenously at a rate of $3.5 \mathrm{~mL} / \mathrm{s}$ with a power injector. No patient received oral contrast material.

\section{Results and discussion}

Patients typically present in their 60 s to 70 s and often have a number of medical comorbidities. In case of occlusive etiology, abdominal pain is the most common presenting symptom (94\%) and patients usually complain of abdominal pain out of proportion to the abdominal examination. Other symptoms include nausea (56\%), vomiting (38\%), diarrhea (31\%), and tachycardia (31\%). In advanced phase, the patient develops peritoneal signs of distention, guarding, rigidity, and hypotension[22-25]. NOMI is suggested by medical history of systemic hypoperfusion due to major surgery, cardiac impairment, hemorrhage, shock, cirrhosis, sepsis, chronic renal disease, medications, and the use of splanchnic vasoconstrictors [26].

\section{Acute arterial mesenteric ischemia}

The diagnosis of AMI can be difficult, because most patients have nonspecific symptoms of abdominal pain. Abdominal pain out of proportion to the findings on physical examination and persisting beyond 2 to 3 hours is the classic pre- sentation [26]. At least the $65 \%$ of cases of intestinal ischemia are due to arterial embolism or thrombosis with blood flow impairment in the superior mesenteric artery (SMA) distribution affecting all or portions of the small bowel and right colon [26]. Most embolic events are thromboembolic in nature and arise from a cardiac source. Risk for a thromboembolic event include atrial tachyarrythmias, low ejection fraction (congestive heart failure, cardiomyopathy), recent myocardial ischemia or infarction, and ventricular aneurysms [7].

Thanks to the development of animal model of mesenteric ischemia, it was possible to explore the physiopathological process that conducts to intestinal infarction, underlining that a specific timing of lesions occurs and it is very important to define this to ensure a correct diagnostic assessment and therapeutic result [27].

Enhanced CT findings are conditioned by the involved tract (some intestinal segments are more sensitive to ischemic injury) by the typology (varying according to the obstructive mechanisms) and by the timing.

In the early phase the presence of emboli or thrombi as filling defect in the lumen of the artery could be found (Figure 1). Their identification can be difficult if they are small and peripherally localized. The injured small bowel loops are contracted in consequence of spastic reflex ileus and intestinal wall shows lacking of/poor enhancement. 


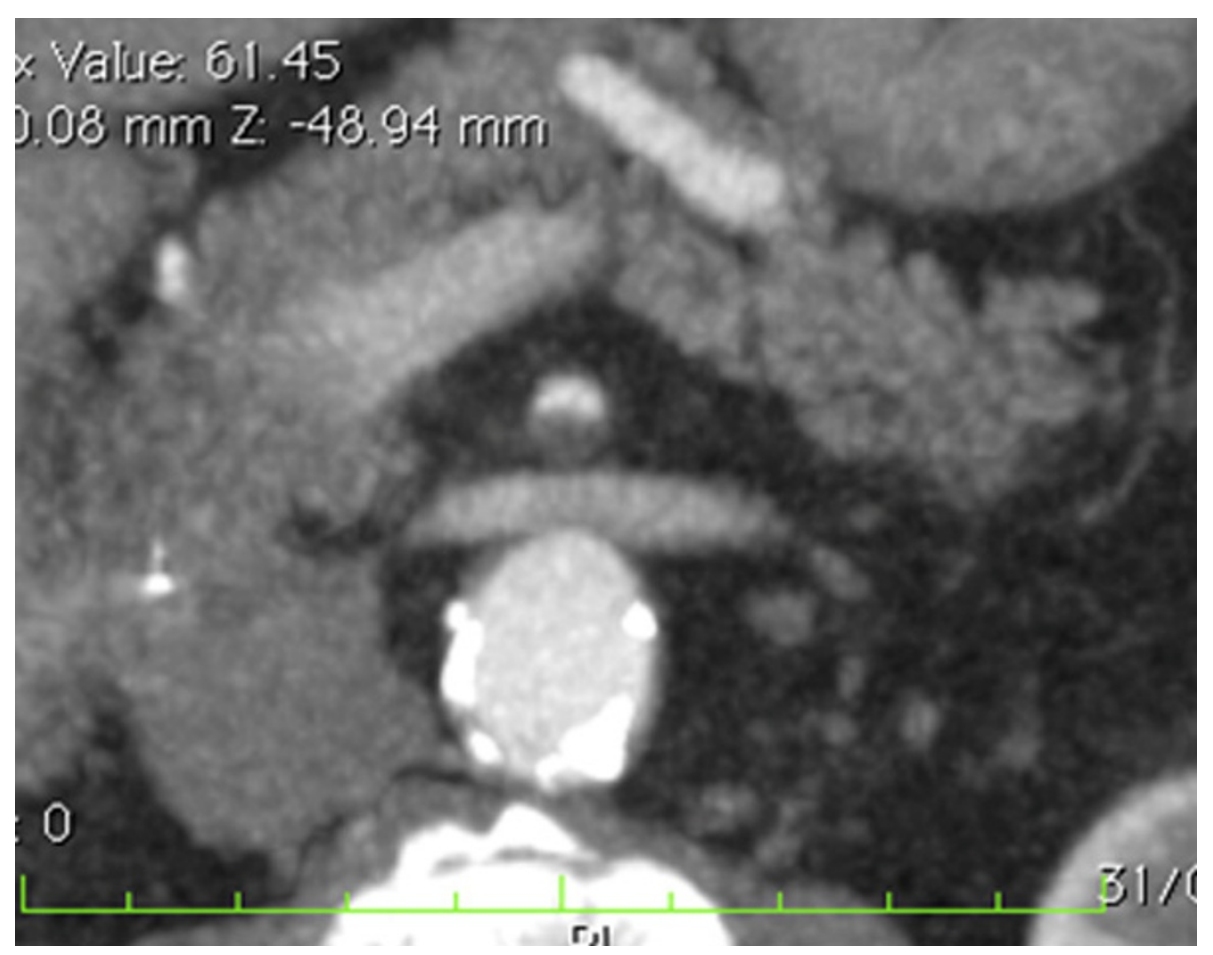

Figure 1 Acute arterial mesenteric ischemia Contrast-enhanced MDCT 2D reconstruction on axial plane shows thrombosis with impairment in the blood flow in the superior mesenteric artery (SMA).

The mesentery is bloodless, due to reduction in vessels caliber $[4,8,11]$.

Hyperperistalsis and hyperactive bowel sounds on auscultation are evident. In case of laparotomy the bowel appear spastic in response to the ischemic damage, with pale mesentery[26].

In the intermediate phase, blood and fluids are drained by the venous system, and the bowel wall become thin, with a typical "paper thin" aspect $[27,28]$; the intestine from the spastic reflex ileus evolves into hypotonic ileus and the loops appear only gas filled, also peritoneal free fluid can be detected [29] (Figure 2). At laparotomy it is possible to find a small amount of serous free fluid in peritoneal cavity, some loops may appear more injured than others with initial change in color from pink to the brownish; the loops appear distended too. In this stage, the pain may be diminishing but becomes more continuous and diffuse. The abdomen becomes distended, and there is more generalized tenderness. Bowel sounds are absent. If the causative factor is not removed, the ischemia rapidly evolves into infarction and the patient clinical picture worsens with fluid, electrolyte and $\mathrm{pH}$ alterations. Air-fluid levels appear as progression from hypotonic reflex ileus in paralytic ileus [11]. Unfortunately, many patients are diagnosed in this stage because they are overlooked or not identified in previous phases. The wall necrosis lead to parietal, mesenteric, and even portal pneumatosis [29] or perforation with pneumo-peritoneum, retro-pneumo-peritoneum; the presence of free fluid in the abdominal cavity [30-33] is due to increased hydrostatic pressure inside the intestinal loops that allows extravasation of plasma and to the peritoneal reaction to the ischemic injury. At laparotomy serous or hemorragic free fluid is found, the intestine appears charcoal black due to necrosis, and the loops are dilated. If the extent of damage is still limited, a bowel resection can be performed, even if in the majority of cases the damage is so extensive that the prognosis is poor $[34,35]$.

\section{Acute venous mesenteric ischemia}

AVMI account for $10 \%$ of cases of intestinal ischemia [36]. Impaired venous drainage disease presents a less acute symptomatology than arterial ischemia, even if both macroscopical and CT findings are more evident and striking if compared with arterial etiology[11,36]. The impairment in the intestinal vein drainage due to SMV occlusion causes vascular engorgement, swelling, and hemorrhage of the bowel wall, with extravasation of fluid to the peritoneal cavity; also mucosal edema and punctate hemorrhage that progress to widespread hemorrhages may be found at surgical exploration. Progression of the thrombosis and inadequate collateral circulation leads to infarction of the jejunum and the ileum [37]. 


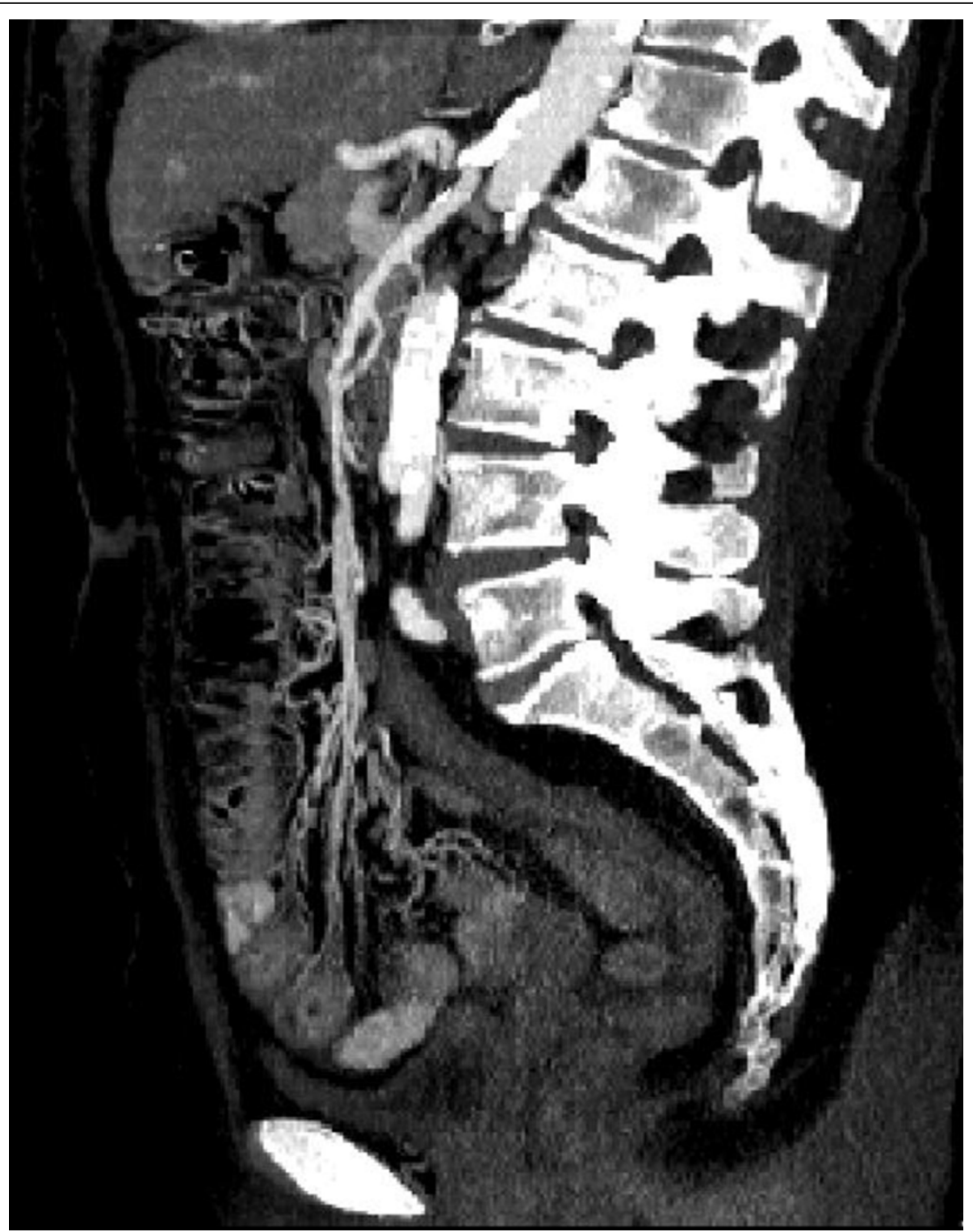

Figure 2 Acute arterial mesenteric ischemia. Contrast-enhanced MDCT 2D reconstruction on sagittal plane in early phase: the CT shows the presence of emboli or thrombi as filling defect in the lumen of the artery. If they are small and peripherally localized, the identification can be difficult. The loops of injured small bowel are contracted in consequence of spastic reflex ileus and intestinal wall shows lacking of/poor enhancement. The mesentery is bloodless, due to reduction in caliber of the vessels and apparently in number.

At CT the thrombus may be seen in the SMV [26], in early phase the main findings are represented by mural thickening, intramural hemorrhage, and submucosal edema. The target appearance of the ischemic bowel at CT consists in an inner hyperdense ring due to mucosal hypervascularity, hemorrhage, and ulceration, a middle hypodense edematous submucosa and a normal or slightly thickened muscularis propria. In this phase the intestine and the mesentery are dark red colored and congested, free fluid is present (Figure 3a-b). If the vascular impairment persists there is an increase of hemorragic free fluid, bowel wall becomes necrotic and peritonitis develop. So the main CT findings are: mural thickening of the involved segments, peritoneal fluid, and mesenteric engorgement. In late stage venous thrombosis, absence of mural enhancement, and the presence of fluid and gas may be evident in the mesenteric and portal veins, bowel wall, and sub-peritoneal or peritoneal space. At surgical exploration the injured loops appear manifestly necrotic. A resection may not be enough to save the patient if the damage is very extensive $[11,26,38]$. 


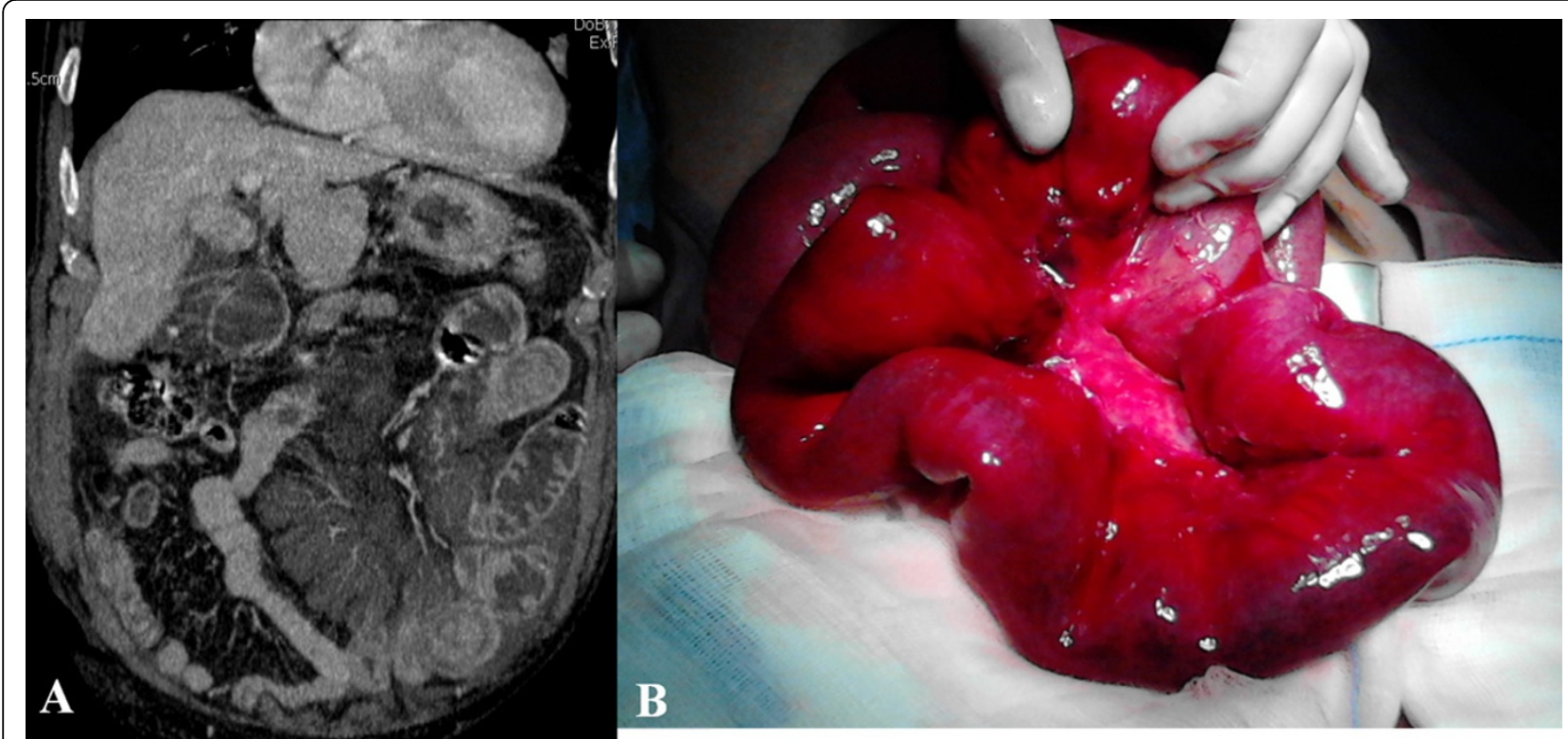

Figure 3 Acute venous mesenteric ischemia Contrast-enhanced MDCT 2D reconstruction on coronal plane in cases of mesenteric venous thrombosis (a) confirmed at surgery (b).

\section{NOMI}

NOMI represents the $20-30 \%$ of all cases of acute mesenteric ischemia [39-43] and comprises the forms of mesenteric ischemia with no occlusion of the mesenteric artery or vein in the area of bowel necrosis $[44,45]$. NOMI is commonly caused by decreased cardiac output resulting in splanchnic hypoperfusion. It generally affects patients over 50 years of age suffering from myocardial infarction, congestive heart failure, aortic insufficiency, and renal or hepatic diseases $[39,40,45]$. During low flow states, the entire intestine can be damaged, but the small intestine and the right colon seem to be more sensitive to the states of shock [46-48]. Since the reduction in blood flow affects both the SMA and IMA, all collateral circulations are ineffective. The ischemic lesions and imaging findings have a similar evolution in the small and in the large intestine. In the small intestine, the CT and surgical findings are the same of AAMI if the blood pressure is not restored. In the early phase the main finding is represented by the spastic reflex ileus due to semilunar fold contraction in response to the ischemia, mesenteric vasoconstriction may be seen as early as $10 \mathrm{~min}$ after the onset of hypotension [39] (Figure 4a-b). At enhanced CT, the mesenteric vessels appear patent and the intestinal wall shows a reduction of the enhancement [11]. Surgical intervention could be required if the ischemic damage progresses. In the intermediate phase the bowel wall of both small and large bowel appear thinned [44] due to inefficacy to collateral circulation. All loops are dilated only gas filled and the transition from spastic ileus to hypotonic ileus is detected. The mesentery appear pale and there is also lack of enhancement of the intestinal wall $[11,29,39]$. If the blood pressure is restored, the intestine is reperfused and the findings depends on the severity of the ischemic damage. The edema of the wall cause low attenuation to enhanced CT and the typical "target sign". A normal enhancement of the intestinal mucosa is a sign of bowel life [49-51]. In the late phase prolonged ischemia, ineffective reperfusion or reperfusion injury, however, can lead to trans-mural necrosis. The intestinal segments appear dilated and distended by air-fluid levels, resulting in paralytic ileus. The absence of enhancement is a sign of ineffective reperfusion which suggests the need for a surgical resection. In the NOMI, due to its pathogenesis, there is also an ischemic involvement of parenchymatous organs (liver, spleen, kidney) that should be carefully investigated [52].

\section{Ischemia/Reperfusion injury}

Ischemia-reperfusion injury (I/R) of the intestine is an important factor associated with a high morbidity and mortality [53]. It may represent the consequence of revascularization after AAMI or of restored blood pressure after low flow states (NOMI). The initial damage caused by ischemia is further worsened by reperfusion [53]; paradoxically, restoration of blood flow to the ischemic tissue initiates a cascade of events that may lead to additional cell injury known as reperfusion injury due to the development of reactive oxygen species. This reperfusion damage frequently exceeds the original ischemic insult [54]. Consequently, many cases of intestinal I/R develop into shock, 


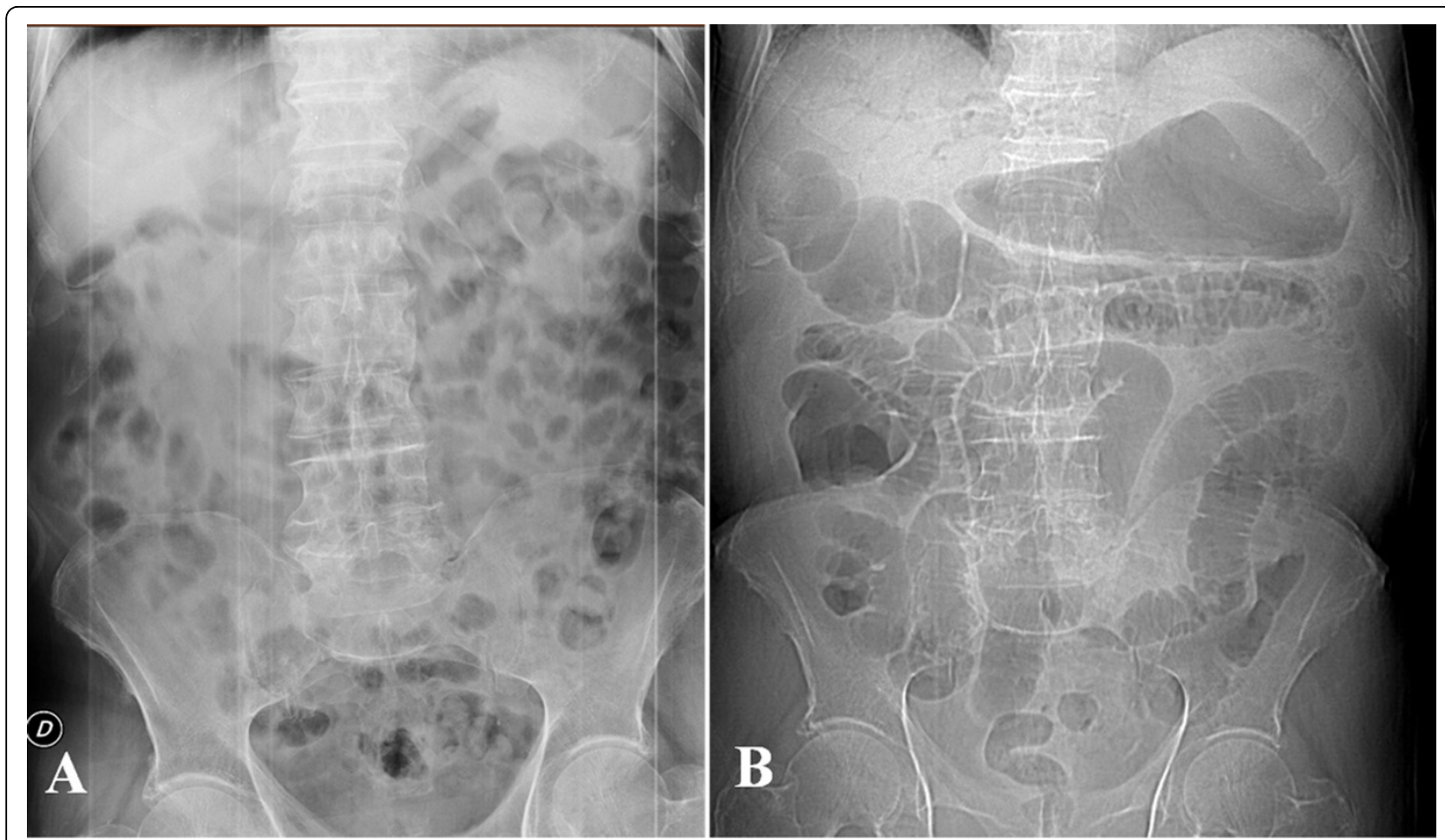

Figure 4 NOMI. Plain abdominal film shows in early phase: ischemia due to vasoconstriction of the splanchnic vessels leading to spastic reflex ileus(a) and in intermediate phase: the bowel wall of both small and large bowel appear thinned (b).

multiple organ failure, and death [22,27,55,56]. Distinguish between mesenteric ischemia with and without reperfusion have a great clinical importance because these conditions have different therapeutic approaches [57,58]. When reperfusion occurs, the reperfused intestine may have a different pattern [59-65]; due to the microcirculation injury there is extravasation of plasma and red blood cells with hemorrhagic foci, the CT and surgical findings are similar to those of AVMI with bowel wall thickening, target sign, free hemorragic fluid and change in color of the bowel wall. The entity and extension of damage are related with the duration and degree of ischemia; they may progress to the necrosis of the entire wall if reperfusion is ineffective or in restored bowel wall condition and free fluid resorption in case of timely and effective reperfusion [26].

\section{Conclusions}

The radiological findings of mesenteric ischemia have different course in case of different etiology. In venous etiology the progression of damage results faster than arterial even if the symptomatology is less acute; bowel wall thickening is an early finding and easy to detect, simplifying the diagnosis. In arterial etiology the damage progression is slower than in venous ischemia, bowel wall thinning is typical but difficult to recognize so diagnosis may be hard. In the NOMI before/without reperfusion the ischemic damage is similar to AAMI with additional involvement of large bowel parenchymatous organs. In reperfusion after NOMI and after AAMI the CT and surgical findings are similar to those of AVMI, and the injured bowel results quite easy to identify. The prompt recognition of each condition is essential to ensure a successful treatment.

\section{Competing interests}

The authors declare that they have no competing interests.

\section{Authors' contributions}

FI: conceived the study, carried out the examinations, analyzed and interpreted the data, drafted the manuscript.

AR: conceived the study, carried out the examinations, analyzed and interpreted the data.

DB: conceived the study, carried out the examinations, analyzed and interpreted the data.

GG: critically revised the manuscript.

GDG: critically revised the manuscript.

MR: critically revised the manuscript.

PF: conceived the study and critically revised the manuscript.

RG: conceived the study, analyzed and interpreted the data, critically revised the drafted manuscript.

All authors read and approved the final manuscript.

\section{Authors' information}

FI: Resident in Radiology Training Program at Second University of Naples AR: Post-Doctoral Fellow in Radiology at Second University of Naples DB: Resident in Radiology Training Program at Second University of Naples GG: Resident in Radiology Training Program at Second University of Naples GDG: Resident in Radiology Training Program at Second University of Naples 
MR: Assistant Professor of Radiology, University of Rome "Sapienza" PF: Associate Professor of Radiology at University of Turin RG: Full Professor of Radiology, Second University of Naples

\section{Acknowledgements}

This article has been published as part of BMC Surgery Volume 13 Supplement 2, 2013: Proceedings from the 26th National Congress of the Italian Society of Geriatric Surgery. The full contents of the supplement are available online at http://www.biomedcentral.com/bmcsurg/supplements/13/S2

\section{Authors' details}

${ }^{1}$ Department of Internal and Experimental Medicine, Magrassi-Lanzara, Institute of Radiology, Second University of Naples, Naples, Italy. ${ }^{2}$ Department of Radiology, Azienda Ospedaliera Sant'Andrea, Rome, Italy. ${ }^{3}$ Institute of Radiology, University of Turin, Turin, Italy.

Published: 8 October 2013

\section{References}

1. Cattaneo F, laccio A, Guerra G, Montagnani S, Ammendola R: NADPHoxidase-dependent reactive oxygen species mediate EGFR transactivation by FPRL1 in WKYMVm-stimulated human lung cancer cells. Free Radic Biol Med 2011, 51(6):1126-36, Sep 15.

2. Testa D, Guerra G, Marcuccio G, Landolfo PG, Motta G: Oxidative stress in chronic otitis media with effusion. Acta Otolaryngol 2012, 132(8):834-7, Aug.

3. Conti V, Russomanno G, Corbi G, Guerra G, Grasso C, Filippelli W, Paribello V, Ferrara N, Filippelli A: Aerobic Training Workload Affects Human Endothelial Cells Redox Homeostasis. Med Sci Sports Exerc 2013, 45(4):644-53, Apr.

4. Mazzei MA, Mazzei FG, Marrelli D, Imbriaco G, Guerrini S, Vindigni C, Civitelli S, Roviello F, Grassi R, Volterrani L: Computed tomographic evaluation of mesentery: diagnostic value in acute mesenteric ischemia. J Comput Assist Tomogr 2012, 36(1):1-7, Jan-Feb.

5. A Elder K, Lashner BA, Solaiman FAL: Clinical approach to colonic ischemia. Cleveland Clinic Journal of medicine 2009, 76(7):401-409.

6. Wyers MC: Acute mesenteric ischemia: diagnostic approach and surgical treatment. Seminars in vascular surgery 2010, 23(1):9-20, Mar.

7. Wiesner W, Khurana B, Ji H, Ros PR: CT of acute bowel ischemia. Radiology 2003, 226:635-650

8. Furukawa A, Kanasaki $\mathrm{S}$, Kono $\mathrm{N}$ et al: $\mathrm{CT}$ diagnosis of acute mesenteric ischemia from various causes. AJR 2009, 192:408-416.

9. Wasnik A, Kaza RK, Al-Hawary MM, Liu PS, Platt JF: Multidetector CT imaging in mesenteric ischemia-pearls and pitfalls. Emergency radiology 2011, 18(2):145-56.

10. Blachar A, Barnes S, Adam SZ, Levy G, Weinstein I, Precel R, Federle MP et al: Radiologists' performance in the diagnosis of acute intestinal ischemia, using MDCT and specific CT findings, using a variety of CT protocols. Emergency radiology 2011, 18(5):385-94.

11. Romano S, Lassandro F, Scaglione M, Romano L, Rotondo A, Grassi R: Ischemia and infarction of the small bowel and colon: spectrum of imaging findings. Abdominal imaging 2006, 31(3):277-92.

12. Reginelli A, Pezzullo MG, Scaglione M, Scialpi M, Brunese L, Grassi R: Gastrointestinal disorders in elderly patients. Radiologic clinics of North America 2008, 46(4):755-71.

13. Moccia F, Bonetti E, Dragoni S, Fontana J, Lodola F, Berra Romani R, Laforenza U, Rosti V, Tanzi F: Hematopoietic progenitor and stem cells circulate by surfing on intracellular $\mathrm{Ca}^{2+}$ waves: A novel target for cellbased therapy and anti-cancer treatment? Curr Signal Transd T 2012, 7(2):161-176.

14. Moccia F, Lodola F, Dragoni S, Bonetti E, Bottino C, Guerra G, Laforenza U, Rosti $\mathrm{V}$, Tanzi $\mathrm{F}: \mathrm{Ca}^{2+}$ signalling in endothelial progenitor cells: a novel means to improve cell-based therapy and impair tumor vascularisation. Curr Vasc Pharmacol 2012.

15. Moccia F, Dragoni S, Lodola F, Bonetti E, Bottino C, Guerra G, Laforenza U, Rosti $\mathrm{V}$, Tanzi F: Store-dependent $\mathrm{Ca}^{2+}$ entry in endothelial progenitor cells as a perspective tool to enhance cell-based therapy and adverse tumour vascularization. Curr Med Chem 2012, 19(34):5802-5818.

16. Sanchez-Hernandez Y, Laforenza U, Bonetti E, Fontana J, Dragoni S, Russo M, Avelino-Cruz JE, Schinelli S, Testa D, Guerra G, et al: Store-operated $\mathrm{Ca}^{2+}$ entry is expressed in human endothelial progenitor cells. Stem Cells Dev 2010, 19(12):1967-1981.

17. Lodola F, Laforenza U, Bonetti E, Lim D, Dragoni S, Bottino C, Ong HL, Guerra G, Ganini C, Massa M, et al: Store-operated $\mathrm{Ca}^{2+}$ entry is remodelled and controls in vitro angiogenesis in endothelial progenitor cells isolated from tumoral patients. PloS One 2012, 7(9):e42541.

18. Dragoni S, Laforenza U, Bonetti E, Lodola F, Bottino C, Berra-Romani R, Bongio GC, Cinelli MP, Guerra G, Pedrazzoli P, et al: Vascular endothelial growth factor stimulates endothelial colony forming cells proliferation and tubulogenesis by inducing oscillations in intracellular $\mathrm{Ca}^{2+}$ concentration. Stem Cells 2011, 29(11):1898-1907.

19. Dragoni S, Laforenza U, Bonetti E, Lodola F, Bottino C, Guerra G, Borghesi A, Stronati M, Rosti V, Tanzi F, Moccia F: Canonical Transient Receptor Potential 3 channel triggers VEGF-induced intracellular ca2+ oscillations in endothelial progenitor cells isolated from umbilical cord blood. Stem Cells and Development 2013, 22(19):2561-2580.

20. Reginelli A, Mandato Y, Solazzo A, Berritto D, lacobellis F, Grassi R: Errors in the radiological evaluation of the alimentary tract: part II. Semin Ultrasound CT MR 2012, 33(4):308-17, Aug.

21. Mandato $Y$, Reginelli A, Galasso R, lacobellis F, Berritto D, Cappabianca S: Errors in the Radiological Evaluation of the Alimentary Tract: Part I. Seminars in Ultrasound, CT and MRI 2012, 33(4):300-307.

22. Paterno F, Longo WE: The etiology and pathogenesis of vascular disorders of the intestine. Radiol Clin North Am 2008, 46(5):877-85, Sep.

23. Brandt $L J$, Feldman M, Friedman LS, Brandt LJ: Intestinal ischemia. Gastrointestinal and liver disease. 8 edition. Philadelphia: Saunders; 2006, 2563-88.

24. Yasuhara $\mathrm{H}$ : Acute mesenteric ischemia: the challenge of gastroenterology. Surgery today 2005, 35(3):185-95.

25. Martinez JP, Hogan GJ: Mesenteric ischemia. Emerg Med Clin North Am 2004, 22:909-28.

26. Gore RM, Yaghmai V, Thakrar KH, Berlin JW, Mehta UK, Newmark GM, Miller FH: Imaging in Intestinal Ischemic Disorders. Radiologic Clinics of North America 2008, 46(5):845-875.

27. Berritto D, Somma F, Landi N, Cavaliere C, Corona M, Russo S, Fulciniti F, et al: Seven-Tesla micro-MRI in early detection of acute arterial ischaemia: evolution of findings in an in vivo rat model. La Radiologia medica 2011, 116(6):829-41.

28. Hou CK, Mak CW, Tzeng WS, Chang JM: CT of small bowel ischemia. Abdominal imaging 2004, 29(1):18-22.

29. Grassi R, Di Mizio R, Pinto A, Romano L, Rotondo A: Serial plane abdominal film findings in the assessment of acute abdomen: spastic ileus, hypnotic ileus, mechanical ileus and paralytic ileus. Radiol Med 2004, 108(1-2):56-70, Jul-Aug.

30. Giannoni MF, Citone M, Rossi M, Speziale F, David V: Role of contrastenhanced ultrasound in the follow-up of endo-vascular aortic aneurysm repair: an effective and safe surveillance method. Curr Pharm Des 2012, 18(15):2214-22.

31. Cappabianca S, Granata V, Di Grezia G, Mandato Y, Reginelli A, Di Mizio V, Grassi R, Rotondo A: The role of nasoenteric intubation in the MR study of patients with Crohn's disease: Our experience and literature review [II ruolo dell'intubazione naso-enterica nella tecnica di studio RM nei pazienti con morbo di Crohn: nostra esperienza e review della letteratura]. Radiologia Medica 2011, 116(3):389-406

32. La Torre M, Ramacciato G, Nigri G, Balducci G, Cavallini M, Rossi M, Ziparo V: Post-operative morbidity and mortality in pancreatic surgery. The role of surgical Apgar score Pancreatology 2013, 13(2):175-9, Mar-Apr.

33. Angelelli G, Scardapane A, Memeo M, lanora AAS, Rotondo A: Acute bowel ischemia: CT findings. European Journal of Radiology 2004, 50:37-47.

34. Barmase M, Kang M, Wig J, Kochhar R, Gupta R, Khandelwal N: Role of multidetector $\mathrm{CT}$ angiography in the evaluation of suspected mesenteric ischemia. Eur J Radiol 2011, 80(3):e582-7, Dec.

35. Tshomba Y, Coppi G, Marone EM, Bertoglio L, Kahlberg A, Carlucci M, Chiesa R: Diagnostic laparoscopy for early detection of acute mesenteric ischaemia in patients with aortic dissection. Eur J Vasc Endovasc Surg 2012, 43(6):690-7, Jun.

36. Somma F, Berritto D, lacobellis F, Landi N, Cavaliere C, Corona M, Russo S et al: 7T $\mu \mathrm{MRI}$ of mesenteric venous ischemia in a rat model: Timing of the appearance of findings. Magnetic resonance imaging 2013, 31(3):408-13. 
37. Romano S, Niola R, Maglione F, Romano L: Small bowel vascular disorders from arterial etiology and impaired venous drainage. Radiol Clin North Am 2008, 46(5):891-908, Sep.

38. Romano S, Romano L, Grassi R: Multidetector row computed tomography findings from ischemia to infarction of the large bowel. Eur J Radiol 2007, 61:433-41.

39. Trompeter M, Brazda T, Remy CT, Vestring T, Reimer P: Non-occlusive mesenteric ischemia: etiology, diagnosis, and interventional therapy. European radiology 2002, 12(5):1179-87.

40. Kniemeyer HW: Mesenterialin- farkt: wann braucht man den Gefässchirurgen? Zentralb/ Chir 1998, 123:1411-1417.

41. Bruch H-P, Habscheid W, Schindler G, Schiedeck THK: Nichtocclusive ischämische Enteropathie: Diagnose, Differentialdiagnose und Therapie. Langenbecks Arch Chir, Suppl 2: 317-321.

42. Bruch H-P, Broll R, Wünsch P, Schindler G: Zum Problem der nichtokklusiven ischämischen Entero- pathie (NOD): Diagnose, Therapie und Prognose. Chirurg 1989, 60:419-425.

43. Hirner A, Häring R, Hofmeister M: Acute Mesenteric vascular occlusions. Chirurg 1987, 58(9):577-84, Sep.

44. Woodhams R, Nishimaki H, Fujii K, Kakita S, Hayakawa K: Usefulness of multidetector-row CT (MDCT) for the diagnosis of non-occlusive mesenteric ischemia (NOMI): assessment of morphology and diameter of the superior mesenteric artery (SMA) on multi-planar reconstructed (MPR) images. European journal of radiology 2010, 76(1):96-102.

45. Cappabianca S, Porto A, Petrillo M, Greco B, Reginelli A, Ronza F, Setola F, Rossi G, Di Matteo A, Muto R, De Rimini ML, Piccolo S, Catalano M, Muto P, De Rosa N, Barra E, De Rosa I, Antinolfi F, Antinolfi G, Caputi M, Brunese L, Grassi R, Rotondo A: Preliminary study on the correlation between grading and histology of solitary pulmonary nodules and contrast enhancement and [18F] fluorodeoxyglucose standardised uptake value after evaluation by dynamic multiphase CT and PET/CT. Journal of Clinical Pathology 2011, 64(2):114-119.

46. Stöckmann H, Roblick UJ, Kluge N, Kunze U, Schimmelpenning $H$, Kujath $P$, Müller G, Bruch H-P: Dia-gnostik und Therapie der nicht- okklusiven mesenterialen Ischämie (NOMI). Zentralb/ Chir 2000, 125:144-151.

47. Tarrant AM, Ryan MF, Hamilton PA, Benjaminov O: A pictorial review of hypovolaemic shock in adults. The British journal of radiology 2008, 81(963):252-7.

48. Lubner M, Demertzis J, Lee JY, Appleton CM, Bhalla S, Menias CO: CT evaluation of shock viscera: a pictorial review. Emergency radiology 2008 15(1):1-11.

49. Landreneau R, Fry W: The Right Colon as a Target Organ of Nonocclusive Mesenteric Ischemia. Archives of Surgery 1990, 125:591-594.

50. Wiesner W, Khurana B, Ji H, Ros PR: CT of acute bowel ischemia. Radiology 2003, 226:635-650

51. Taourel PG, Deneuville M, Pradel JA, Régent D, Bruel JM: Acute mesenteric ischemia: diagnosis with contrast-enhanced CT. Radiology 1996, 199(3):632-636.

52. Jakob SM: Splanchnic Blood Flow in Low-Flow States. Anesthesia \& Analgesia 2003, , 34: 1129-1138.

53. Mallick $\mathrm{H}_{\text {, }}$ Yang W, Winslet MC, Seifalian AM: Ischemia-reperfusion injury of the intestine and protective strategies against injury. Dig Dis Sci 2004, 49:1359-77.

54. Stallion A, Kou TD, Miller KA, Dahms BB, Dudgeon DL, Levine AD: IL-10 is not protective in intestinal ischemia reperfusion injury. J Surg Res 2002, 105(2):145-152.

55. Klein HM, Klosterhalfen B, Kinzel S, Jansen A, Seggewiss C, Weghaus $P$, Kamp M, Töns C, Günther RW: CT and MRI of experimentally induced mesenteric ischemia in a porcine model. J Comput Assist Tomogr 1996 20:254-61.

56. Danse EM, Hammer F, Matondo H, Dardenne AN, Geubel A, Goffette P: Ischémie mésentérique chronique d'origine arterielle : Mise en evidence de reseaux de vicariance par echographie Doppler couleur. Journal de radiologie 2001, 82(11):1645-1649.

57. Takizawa $Y$, Kitazato $T$, Kishimoto $H$, Tomita M, Hayashi M: Effects of antioxidants on drug absorption in in vivo intestinal ischemia/ reperfusion. Eur J Drug Metab Pharmacokinet 2011, 35:89-95.

58. Da Motta Leal Filho JM, Santos ACB, Carnevale FC, De Oliveira Sousa W Jr, Grillo Jr. LSP, Cerri GG: Infusion of Recombinant Human Tissue Plasminogen Activator Through the Superior Mesenteric Artery in the
Treatment of Acute Mesenteric Venous Thrombosis. Annals of Vascular Surgery 2011, 25(6):840.e1-840.e4.

59. Chou CK, Mak CW, Tzeng WS, Chang JM: CT of small bowel ischemia. Abdominal imaging 2004, 29(1):18-22.

60. Asabella Niccoli A, Di Palo A, Notaristefano A, Ciccone M, Ferrari C, Zeppa P, Cortese F, Rubini G: Role of 18F-FDG-PET/CT in the assessment of carotid atherosclerosis. Recenti Prog Med 2012, 103(11):515-9, Nov.

61. Niccoli Asabella A, Di Palo A, Rubini D, Zeppa P, Notaristefano A, Rubini G: Distribution of 18F-FDG in a patient with evolving abdominal aortic aneurysm. Recenti Prog Med 2012, 103(11):552-4, Nov.

62. Dialetto G, Reginelli A, Cerrato M, Rossi G, Covino FE, Manduca S, Lassandro F: Endovascular stent-graft treatment of thoracic aortic syndromes: A 7-year experience. European Journal of Radiology 2004, 64(1):65-72.

63. La Grutta L, Galia M, Gentile G, Lo Re G, Grassedonio E, Coppolino F, Maffei E, Maresi E, Lo Casto A, Cademartiri F, Midiri M: Comparison of iodinated contrast media for the assessment of atherosclerotic plaque attenuation values by CT coronary angiography: Observations in an ex vivo model. British Journal of Radiology 2013, 86(1021), art. no. 20120238.

64. Basile A, Tsetis D, Montineri A, Puleo S, Massa Saluzzo C, Runza G, Coppolino F, Ettorre GC, Patti MT: MDCT anatomic assessment of right inferior phrenic artery origin related to potential supply to hepatocellular carcinoma and its embolization. Cardiovascular and Interventional Radiology 2008, 31(2):349-358.

65. Stabile lanora AA, Losco M, Fonio P, Zeppa P, Pizza NL, Cuccurullo V: Actual role of $M R$ in the small bowel studies: dynamic sequences and bowel distension. Recenti Prog Med 2012, 103(11):422-5, Nov.

doi:10.1186/1471-2482-13-S2-S51

Cite this article as: Reginelli et al:: Mesenteric ischemia: the importance of differential diagnosis for the surgeon. BMC Surgery 2013 13(Suppl 2):S51.

\section{Submit your next manuscript to BioMed Central and take full advantage of:}

- Convenient online submission

- Thorough peer review

- No space constraints or color figure charges

- Immediate publication on acceptance

- Inclusion in PubMed, CAS, Scopus and Google Scholar

- Research which is freely available for redistribution

Submit your manuscript at www.biomedcentral.com/submit
C Biomed Central 